\title{
Medical Tourism-Issues in Nigeria
}

\author{
OBUH Joy $^{1 *} \quad$ Onobun Marie-Terese ${ }^{2} \quad$ Eluwa Onyeje $^{3} \quad$ Azama Abigael Alao $^{1}$ \\ Aguele Oluwakemi Omolara ${ }^{1}$ \\ 1.Department of Hospitality Management, National Institute for Hospitality and Tourism (South-South) Zonal \\ Campus Benin City \\ 2.Department travel and Tourism, National Institute for Hospitality and Tourism (South-South) Zonal Campus \\ Benin City
}

\begin{abstract}
This study was carried out with the aim of evaluating the effects medical tourism has on Nigeria. This was done focusing on the trends on three major concerns which are: the effect of medical tourism on the health status of Nigerians, the effect of medical tourism on Nigeria's economy and lastly, why medical tourism by Nigerians despite the development in our medical sector. Data for this study were collected majorly from secondary sources and the Desk review method of data analysis was used. This primarily entails the examination and evaluation of several studies using the Scoping review research design of collecting and collating important information for the research. This allowed for expansion of knowledge on other key areas that were not related to the scope of study, such as social health development and several others. Findings revealed that indeed, medical tourism by Nigerians has had some effects on several sectors of the country, one of which is a reduction in the revenue for sustaining the source country's (Nigeria) local health sector and as a result, leads to poor performance on the medical officers, as they are short of logistics and facilities and in turn leads to lack of trust in medical practitioners and also high mortality rate. If the millions of Naira spent by some Nigerian government officials and the Nigerian elites on medical tourism abroad, are put into effective infrastructural development and are made to receive medical treatments here in Nigeria, they would indeed be doing the economy and the general image of the nation's health status /sector a lot of good.
\end{abstract}

Keywords: Medical tourism, health, scoping review research design

DOI: $10.7176 / \mathrm{DCS} / 10-8-05$

Publication date:August $31^{\text {st }} 2020$

\section{Introduction}

Nigeria, a country situated in West Africa with a population over 190 million citizens is blessed to be situated in the rain forest region, which provides mangroves and several other natural habitat for tourist attraction, where Nigeria seems not to be thriving is on a major sector, which is medical tourism. The issue of medical tourism in Nigeria, is said to be on the down side, whether domestic or outbound, people who wish to preserve their lives or enhance physical appearance, are seeking it elsewhere if they cannot get it in their home country or rather say, place of residence.

The consumption of health care services in a foreign land in better term "Medical Tourism" is not a new phenomenon. For as early as records and historians can tell, people have travelled far distance seeking healings or treatments from well-known physicians, prophets, waters, fountains or baths. This movement of people or patients from their environment of residence in pursuit of medical and health care services lead to the coinage of the phenomenon "Medical Tourism". During the $19^{\text {th }}$ century, in Europe for example there was a fashion for the growing middle class to travel to spa towns to take the water, which was believed to have health enhancing qualities .During the $20^{\text {th }}$ century, wealthy people from developing parts of the world travelled to developed nations to access better facilities and highly trained medics. However, the shifts that are currently undergoing with regard to medical tourism is somewhat different from earlier forms of health-related travel. An example of such a shift could be found on several medical journals on how most Americans travel to Mexico or even India for some specific treatments, not because America as a whole, which is one of the worlds most developed nation do not have good hospitals, doctors or surgeons but simply because it is either more affordable to get these health care services abroad than within their country or just for the flare of getting such medical attention abroad. This could be affirmed by an article on Health-torism.com. Which says

The medical tourism industry has seen a major increase in the past decade. Researchers have confirmed that: In 2013, about 75,000 American citizens travelled to India for medical treatment and more than 300,000 went to Latin America. It is estimated that approximately 1.25 million Americans travel abroad in 2014 for medical treatment. American patients are opting to undergo medical treatment abroad for procedures such as: face lifts, heart bypasses and fertility treatments. For many people who require medical treatment, the last thing they want to do is travel. However, due to the high cost of medical treatment in the USA, many American patients are going abroad for medical treatments. Their purpose is to save $50 \%$ to $80 \%$ on medical treatment conducted by doctors who are often trained in the United States, at hospitals that maintain the precise standards of patient care and safety. Nigerians are not left out of this industry. In early times, people travel long distance from their homes to find the 
best midwives, or medicine men, or even travel to bath in certain waters, rivers, streams, fountains, in believe that they would get healed from strange ailments. In modern times, people travel from state to state (particularly teaching Hospitals) and when these hospitals becomes unreliable or for other purposes, the wealthy ones travel out to other African countries, or even outsides the walls of the African continent to get the medical attention desired.

When looking at Medical tourism from the global perspective, Nigeria is not known to be a tourist destination for healthcare, but serves as important source country to destination countries such as India, Turkey, South Africa, United states, United Kingdom, Saudi Arabia and Germany amongst a few. In 2005, the wife of a serving Nigerian president, died after undergoing cosmetic surgery in Spain. Even the current serving president of the country, had to travel to the united kingdom in June 2016 in order to attend to a persistent ear infection. This was done, despite the availability of over 250 ear, nose, and throat specialist in the country. What then is the problem? Since even the elites and national leaders are running abroad for medical treatment. Does this have any economic impact? Or even on the image of the country to other nations.

\section{Medical Tourism}

The term medical tourism is an amalgamation of two distinct services - healthcare and tourism. The World Tourism Organization (1999) defines tourists as people who "travel to and stay in places outside their usual environment for more than twenty-four (24) hours and not more than one consecutive year for leisure, business and other purposes not related to the exercise of an activity remunerated from within the place visited. This definition provides at least a clear understanding between just traveling for leisure and other purposes and traveling for healthcare purposes. This has helped in clearing the confusion that is perceived upon hearing the term "Medical Tourism".

Hanefeld, Horsfall, Lunt, and Smith (2013) Medical Tourism: A Cost or Benefit to the NHS" defines medical tourism as" when consumers elect to travel across international borders with the intention of receiving some form of medical treatment. This treatment may span the full range of medical services, but most commonly includes dental care, cosmetic surgery, elective surgery, and fertility treatment"

Musa, Doshi, Wong, Thirumoorthy (2012), Medical Tourism: The Ethics, Regulation and Marketing of Health Mobility, defined precisely the phenomenon as "All the activities related to travel and hosting a 1tourist who stays at least one night at the destination region, for the purpose of maintaining, improving or restoring health through medical intervention"

Munro (2012) in her book "What is Medical Tourism?" sees the phenomenon as "medical tourism describes the act of people making health choices and accessing health treatments across borders".

Lunt, Smith, Exworthy, Stephen, Horsfall and Mannion (2011) in a study titled "Medical Tourism: Treatments, Markets and Health System Implications: A scoping review." Consider the term medical tourism, "as when consumers elect to travel across international borders with the intention of receiving some form of medical treatment. This treatment may span the full range of medical services, but most commonly includes dental care, cosmetic surgery, elective surgery, and fertility treatment."

Medical tourism is also said to be related to the broader notion of health tourism which, in some countries, has longstanding historical antecedents of spa towns and coastal localities, and other therapeutic landscapes. Some commentators have considered health and medical tourism as a combined phenomenon but with different emphases, Lunt et al., (2011)

Carrera and Bridges (2006), as seen in Lunt et al., (2011), for example, define health tourism as -the organized travel outside one's local environment for the maintenance, enhancement or restoration of an individual's well-being in mind and bodyll.

Medical tourism, just like tourism in general can be viewed from two perspectives: Inbound tourism and Outbound tourism.

\subsection{Research questions}

1. Does medical tourism affects Nigeria's health status?

2. Does medical tourism affect the country's economy?

3. Despite the said development on the medical centres available in a country, why medical tourism in Nigeria?

\subsection{Research Hypothesis}

1. There is no significant effect of medical tourism on Nigeria's economy

2. There is no significant reason for medical tourism by Nigerians.

\subsection{Statement of problem}

One often wonders that despite the magnanimous improvement on our educational system, and hear-say of skilled doctors, the Nigerian Medical sector produces each year. We still hear of persons travelling from state to state and 
even across the borders of Nigeria to receive medical attention from other countries either because of cost, status in the society, unavailability of certain instruments and facilities or the feel that these other places and countries have better health care services. This in return has affected the tourism industry in general. In this study, the researcher aims at elaborating on the issue of medical tourism in Nigeria, and also want to carry out a study on the reason why medical tourism by Nigeria.

\subsection{Aim and Objectives}

In this research work, the researcher's aim is at:

1. Present a clear understanding of the term Medical tourism, through evaluation of several definitions

2. To proffer solution to research question1, which is pertaining to the effects of Medical Tourism to Nigeria's economic growth.

3. To elaborate on the effect and the role of medical tourism in the tourism industry.

\subsection{Relevance of study}

This study being carried out would be a very relevant source of material to other researchers who would want to carry out further studies on medical tourism, and would be of relevance to scholars alike on the subject of medical tourism. As it seeks to provide answers on the current trends in the nation and outside. It would also be relevant to the government in evaluating the effects of medical tourism, and work towards the improvements of our health care facilities as to enhance inbound tourism which will in turn be favourable to the economy.

\subsection{Research Methodology}

This study is guided by the descriptive methodology of a basic research. This entails the desk review method of data analysis of data collected. And also the use of Scoping framework of analysis. Data used were collected from secondary sources. The secondary method, involved the sourcing of materials on already existing studies on medical tourism in Nigeria and a series of selected.

\section{Methodology}

\subsection{Introduction}

This chapter aims to give detailed explanation of the methodology to be employed in this research. It will be conducted to investigate the issue of medical tourism in Nigeria. To achieve the objectives of this study, the outline of this chapter will include;

Research design

Population of study

Sample and sampling techniques

Research instruments

Method of data analysis

\subsection{Research Design}

The research design chosen for this study is a scoping review research design. Scoping review framework represents a methodology that allows assessment of emerging evidence, as well as a first step in research development. This frame work is often credited to Arksey and O'Malley (2005) in an article published, titled "Scoping studies: towards a methodological framework"

Arksey \& O'Malley, presents a six step methodology approach, in carrying out a scoping review, they include:

1. Identify the research questions: what domain needs to be explored?

2. Find the relevant studies, through the usual means: electronic databases, reference lists

(Ancestor searching), websites of organizations, conference proceedings, etc.

3. Select the studies that are relevant to the question(s)

4. Chart the data, i.e. the information on and from the relevant studies

5. Collate, summarize and report the results

6. (Optional) consult stakeholders (clinicians, patients and families, policy makers, or whatever is the appropriate group) to get more references, provide insights on what the literature fails to highlight, etc.

As listed above, this framework, involves first of all, identifying the research questions, what are the problems whose solutions are being sort. A properly outlined research questions, will aid the ease of the next step, which is to sourcing for relevant studies in relation to the questions outlined. Which then leads to the next stage, critical selection of the relevant studies sourced. Presentation of the information gotten from these data files after the third stage and then a compilation, a report and summary is made. The sixth step which is often tagged optional can come in place at any time of the research. In which case the researcher feels a need to verify or source for more information from relevant sources, such as hospitality industries, the government bodies and several others. 


\subsection{Sample and Sampling Techniques}

A sample is a small subset of the total population. According to (Mugenda and Mugenda, 2003) sampling is a careful selection of sub group from the accessible population so as to be a representative of the whole population with relevant characteristics. Online simple random sampling will be used to select work done in medical tourism in the country in other to know the issue of medical tourism in Nigeria and its effect on Nigerian's health status.

\subsection{Research Instrument}

The instrument to be used for this research will be online peoples opinionnaire. That is, opinion either on internet, newspapers, journals etc. It will be used to collect the secondary data needed for the research.

\subsection{Method of Data Analysis}

The data will be analysed with the use of Desk review method of analysis and simple statistical analysis. As depicted by name Desk Research is the research technique which is mainly acquired by sitting at a desk. Desk research is basically involved in collecting data from existing resources also known as secondary data. As explained in an article by Juneja (2017).

\section{Data Presentation and Analysis}

\subsection{Data Analysis and Interpretation on Research Questions}

RQ1: Does medical tourism affect Nigeria's health status?

The data extracted from literature review aim to find out if Medical tourism affects the health status of the country's citizens. Table 1 shows the figures and statistics of the country's population from 2013 to 2018, the number of practicing doctors in the country and the possible number of patients that will be assigned to a doctor. Below the table is the interpretation of the data collected.

Dividing the number of population for each year with the numbers of practicing doctors in the country as at 2018 , it was observed that each doctor in the country will be assigned more patients as against World Health Organization which recommended a ratio of 1:600. The figures in the table above show that the physician-patient ratio in Nigeria ranges from 1:4000 to 1:5000 and above from 2013 till date. Statistics from the graph above shows that as years progressed, more patients was been assigned to a doctor, leading to inadequacy of man power in medical field to cater for the citizen's health status. From the data, the number of patients to a doctor in 2018 and that of 2013 differs with total of 746 patients. This inadequacy of doctors in the country with rapid population growth will in no means prompt people to access medical help from other country with low physician-patient ratio. According to World Health Organization, a country with low physician-patient ratio has worse disease outcomes and life expectancy. This is so, because, the numbers of practicing physicians in the country are not enough to accommodate the population of the country and when this happens, there is bound to be loss of life, low and insignificant health status of the country's citizens. Despite the insufficient physicians at our disposal, Nigeria medic still travel to other country in search of greener pasture and also to a place where they could access the needed facilities. Statistics shows that $93.0 \%$ of Nigerian medical doctors travelled to United Kingdom, $86.0 \%$ to United State, $60.0 \%$ to Canada while 1.0 to Qatar. Drawn from the British Government in 2018 from premium time (The Guardian), Nigeria medics constitute 3.9 percent of the 137,000 foreign staff of 202 nationalities working alongside British doctors (Chukwuma 2018). And in 2016, among the 72,000 numbers of doctors trained, 20,000 travelled abroad (S/N:Serial number GDP: Gross Domestic Product) leaving some few doctors to determine the health status of the mass population in country. It is evident that the number of doctors in the country is insignificant as compare to the nation's population, thereby putting the citizen's health at risk. So also, the fact that Nigeria elites (politicians) rely more on foreign treatment than the ones in their country goes a long way in sshowing how much they less believed in the competence of Nigeria medics.

According to the former Minister of Health, in the person of Mr Chukwu Oyenbuchi, "skill proficiency becomes a victim as both trainers and trainees are not exposed to enough cases and of course quality of care suffers". This is quite plain and the resultant effect of medical tourism, nobody in his or her right mind would want to be a lab rat at an institution with less medical expertise and durable facilities, thereby leading to an increase in mortality rate as people would be left either stranded or seek local herbal healing methods, which often fails. There are even cases of wrong diagnosis due to inexperience on the part of the medical practitioner, leading eventually to wrong prognosis and a total relapse in the health of such a patient. During the course of this study, the researcher came across a patient at one of the biggest teaching hospitals in Nigeria, who obviously had appendix but was wrongly diagnosed of infections by a young doctor who apparently had little experience with such cases and was being given antibiotics which heightened his situation. This is the alarming case of Nigeria today, which is why the health minister in a conference in 2017 at Obafemi Awolowo University, Ile Ife, beckons on the federal government to support the health sector by proving standard medical equipment that will compete with those found outside Nigeria, so that people will patronise local medical facilities. 


\subsection{RQ2. "Does Medical tourism have an effect on Nigeria's economy?}

Drawing conclusively from the answer to the problem provided by question one, and evidence from available reports indicates that medical tourism doesn't just affect the health sector, it variably has an adverse effect on the economic sector as well. According to Epundu et al (2017) medical tourism has far reaching economic and health system implications, in both source and destination countries. When high-income patients leave a country, it leads to a reduction in revenue for sustaining the country's local health services, leading to Losses of such clients also reduce the pressure to invest in certain beneficial health technologies, as well as reduce political support for developing the health system of the country. Take the case of the Nation's own President traveling miles in recent times to receive healthcare in other country. Assuming he doesn't just receives the healthcare alone, feeding cost, travel cost, lodging cost and all. These are expenses that could very well been avoided if the focus was on the development of the country's medical health sector, thereby reinvesting the money in one's country instead of enriching another nation while the local health care suffers.

During the opening ceremony of the 2017 Faculty of Clinical Sciences $10^{\text {th }}$ faculty week and Scientific Conference, obafemi Awolowo University, Ile-ife with theme; Medical Tourism in Nigeria-" the former minister of health, Professor Oyenbuchi Chukwu, said that Nigeria was losing about N175 billion annually to medical tourism. He also said that the wasted funds was more than 50 per cent of the proposed total budget for 2018 for the federal health sector.

According to him also the health sector is being denied the much needed funding which is affecting its development. And as a result of this, he noted that "Outbound medical tourism gradually becomes the preference of patients, the local sector loses the confidence of the populace resulting in low esteem and morale among health personnel" in other words, outbound medical tourism, has more negative effects in general and should be discouraged.

In another article examined, as published on THE POINT news media, it was reported that The Nigerian Medical Association (NMA), during its National Executive Committee (NEC) meeting in Sokoto in 2013, gave the national pecuniary loss suffered by Nigerians as a result of medical tourism at $\$ 800$ million (N125 billion), while the Association of Medical Laboratory Scientists of Nigeria (AMLSN) settled for N250 billion as the annual loss from medical tourism, within the same period. Similarly, in 2014the Federal Ministry of Health, through its Director of planning, Research and Statistics, Dr. Ngozi Azodoh, disclosed that public officers alone spent N198.95 billion on medical tourism. From the foregoing, it is very obvious that Nigeria has lost significant sums of money to medical tourism. Indications also shows that such situations will continue unabated as long as the government does not put the necessary measures to address this matter.

\subsection{RQ3 why medical tourism?}

The answer to this question, could already be seen lurking out of the above. From the data collected, medical tourism by Nigerians have been affixed to so many reasons. A few of which will be listed below.

1. Social status: The believe or saying, that one should act one's pocket is the sole reason why many elites today have refused patronizing home based medical systems. It is now a common trend for Nigerian celebrities to carry out their childbirth in the US or any other Western world country other than here in Nigeria were millions of children are delivered daily without complications.

2. Loss of confidence in the medical sector: Another reason why most Nigerians are running out to other countries to receive medical care, also fall within the woes of loss of confidence. Many persons do not believe they can get quality health care in the dilapidating structures they see around them called hospitals and also, they don't expect graduates from Nigerian institutes with very little experience and results of failing system to be able to provide quality healthcare for them.

3. Privacy: people with certain kinds of ailments, with the fear of being exposed and ridiculed by the public often prefer to get their treatment elsewhere where they are not known to ensure $100 \%$ privacy policy is kept.

4. Unavailability of certain services and facilities within the county: it is not until recent times that Heart transplants were being done in Nigeria, India was the home to about $60 \%$ of heart surgery performed on Nigerians. According to Indian high commission in Nigeria, 18,000 (47\%) Nigerians that visited India in the year 2012alone, did so for medical treatment with an estimated cost of N41.6 billion in foreign exchange in the process (Daily Independent Newspaper, 2014) as gotten from Abubakar et al (2018).

5. Incessant strike: this is one of the woes of our medical system, the tendency of meeting up with a booked medical appointment without hearing that they are on strike is very low. This is what many person s who are able to afford medical care in other countries often go for it. Many death cases have been recorded due tom Doctors going on strike in Nigeria for one reason the other, and the government does not seem to be doing anything about it.

6. Cost and efficiency in result: for the fear of having spent a whole lot on a medical condition and having the case reoccur due to inefficiency, most people would prefer to take such conditions to places or 
countries that are really known to have specialization in such fields. And also most people would find it cheaper to receive health care in countries like China, India and Canada that have put medical tourism as one of their greatest sources of revenue.

\subsection{Some of the Effects of Medical Tourism}

The main focus of this study, has been linked with issues relating to outbound medical tourism and its effects on Nigeria's economy, health status and the reasons behind it. Having elaborated on that, some of the effects, both positive and negative that have been linked with outbound medical tourism as gotten from the data analyzed are; Positive Effects

1. Patients can have access to treatments not locally provided in their home country

2. Easy access to variety of medical centers and the will to choose a plan suitable for you.

3. Assurance of $100 \%$ success rate as most countries are focusing resources on training expertize on particular fields.

\section{Negative Effects}

1. Medical tourism competes for local healthcare resources

2. Raises concern, about health equity, quality of care, continuity of care, legislation problems, professional codes, and institutional policies with legal and ethical issues.

3. Misusing of government funds in sending patients out for expensive non-elective treatments.

4. Overseas medical treatment is a huge economic burden.

5. Medical tourism encourages illegal transnational medical practices such as illegal organ transplant.

6. Discourages the government in improving local healthcare sectors.

\section{Findings}

Having gone through several studies done on medical tourism both locally and international, it has been observed that medical tourism is never good for a source nation. This renders so many treat to the health service system and systematically drains the economy of its own coin. Another effects of medical tourism that was not discussed in chapter four, is the "brain drain effect" this is when medical Practitioners leave the country to "seek greener pastures" in other countries, this is often because of the unfavourable working conditions, lack of healthy competitions and environment for improvement in our health sector.

Many health care givers are not challenged enough, they are faced with too many restrictions financially, either in their remuneration or their salaries and wages are not paid at the appropriate time. Also, many are restricted to treating only a few types of medical challenges, i.e. malaria with inadequate facility. More worrisome is the erratic nature of the power situation in the country, the nation for the past twenty years have been struggling to generate a constant and steady power supply, or even having to battle with outdated facilities that are due for change and repairs without which might lead to failure or error in results and procedures just because the government has refused to provide funds for their renovations and many more. It was estimated according to the sunnews paper published on the 15 September 2017 that out of over 4000 black medical doctors and nurses in Europe, $80 \%$ of them are Nigerians. This rate is alarming considering the fact that Nigeria is developing and needs these services more than these western countries.

\subsection{Summary}

Nigeria has, over the past decades been at a disadvantaged position for tourist who seek medical attention, worse still, our medical professionals have left the country in droves seeking for a better working condition and this has greatly affected the health sector of Nigeria in terms of the personnel at the country's disposal. Medical tourism like we stated earlier is not a new phenomenon as humans have been known to have travelled from one place to another seeking medical attention. Nigerians are not left out of this beautiful trend, despite the derth of Doctors our medical schools produce every year, Nigerians are known for seeking medical attention outside Nigerian, looking at the statistics, all Nigerian presidents, Governors, Ministers and other wealthy individuals since the democratic dispensation represents the largest chunk of individuals who have gone outside this country seeking medical attention, an ugly trend that must be reversed. The current president spent close to 90 days in England seeking medical attention. The question many of us have asked is what can we do to attract other people into this country on medical tourism? Below are my recommendations

\subsection{Recommendation}

In other to make Nigeria medically attractive to other people in different parts of the world, here are a few recommendation based on our findings.

1) A lot of Nigerians seek better, reliable and affordable medical attention, it is advisable that the government allocate at $30 \%$ of its annual budget to making the health sector a reliable one.

2) Corruption and corrupt practises has been the bane of development of the Nigerian state, this has also 
played out in health sector. A lot of funds have been mismanaged and embezzled by corrupt individuals who have been saddled with the responsibility of taking care of the health sector

3) Putting a round peg in a role hole; a lot of appointments have been made in the health sector that has not enhanced the growth of medical tourism in Nigeria, most people that are place there either know little or nothing about their position, thereby crippling the goals of medical tourism

4) Our political elites needs to start using our medical facilities in other to promote our tourism.

5) The remuneration and welfare of medical personnel should be of importance to the government, medical personnel should be properly taken care of and provided with adequate facility where they work effectively

6) Training and Re training of medical personnel should be of importance to the government. Our government should endeavour to train medical personnel in the global practises of medical field and provide them with up to date facilitates their work

7) Public and private partnership scheme should also be encouraged, investors should be encouraged to come into the country and build world class health care facilities.

8) Government should do more on the anti-corruption war, and it should be extended to the health sector.

9) Medical doctors working with the government should be discouraged from owning a private hospital, as this will not allow them give their maximum employers.

\subsection{Conclusion}

Medical tourism, if it must be fully harnessed maximally, government and private individual must ensure that they do their best to promote it. Rome they said was not built in a day, we don't expect this to be achieved in the shortest period of time. We must work collectively and persistently too to ensure that a Nigeria becomes the tourist hub of those seeking medical attention. If fully harnessed, medical tourism can be generate billions of dollars for a country which only source of revenue is oil.

\section{References}

Abubakar, B., Oluyemi, A., Atalagbe, A. \& Kadiri. (2018). Medical Tourism in Nigeria: Challenges and Remedies to Healthcare System Development. International Journal of Development and Management Review., Vol.13(1).

Carrera, M.P, and Bridges, J.A. (2006). Health and Medical Tourism: What they Mean and Imply for Health Care System. In Health and Ageing. The Geneva Association, vol.5.

Epundu,U.U, Adinma,E.D., Ogbonna,B.O., \& Epundu,O.C . (2017). Medical Tourism, Public Health and Economic Development in Nigeria: Issues and Prospects. In Asian Journal of Medicine and Health, Vol.7(2). Pgs 1-10.

Hanefeld,J, Horsfall,D., Lunt,N. \& Smith,R. . (2013). What do we know about Medical Tourism? A Review of the Literature with diswcussion of its Implication for the UK National Health Service as an example of a Public Health Care Syatem. Journal of Travel Medivine, Vol.21. Pgs 410-417.

Juneja, S. (2017). International Association for study of Pain. In Research Gate, Vol.11.

Lunt, N., Smith, R., Exworthy, M., Stephen,T., Horsfall, D \& Mannion, R. (2011). Treatments, Market and Health System Implication. A Scoping review, Pg 2.

Munro, J. (2012). What is Medical Tourism? Toward a Practical Understanding of Medical Tourism and Medical Travel, Wellness Tourism, Health Tourism and Heqalth Travel . MTQUA, vol.2.

Musa,G., Doshi,R.R, Wong,K.M, Thirumorthy,T. (2012). How Satisfied are Inbound Medical Tourists in Malaysia? A Study of Private Hospitals in Kaula Lumper. Journal of Travel and Tourism Marketing, vol.29. Pgs 629646. ISSN 1054-8408. 
Table 1: Figures of the country's population.

\begin{tabular}{|l|l|l|}
\hline Year & Numbers of people & Ratio \\
\hline 2013 & $170,528,460$ & $170528460 \div 35000=4872$ \\
& & $1: 4872$ \\
\hline 2014 & $175,140,253$ & $\begin{array}{l}175140253 \div 35000=5004 \\
1: 5004\end{array}$ \\
& & $179838974 \div 35000=5138$ \\
& 175138 \\
\hline 2015 & $189,838,974$ & $189635279 \div 35000=5418$ \\
& & $1: 5418$ \\
\hline 2016 & $189,559,502$ & $189559502 \div 35000=5416$ \\
& & $1: 5416$ \\
\hline 2018 & $196,615,054$ & $196615054 \div 35000=5618$ \\
& & $1: 5618$ \\
\hline
\end{tabular}

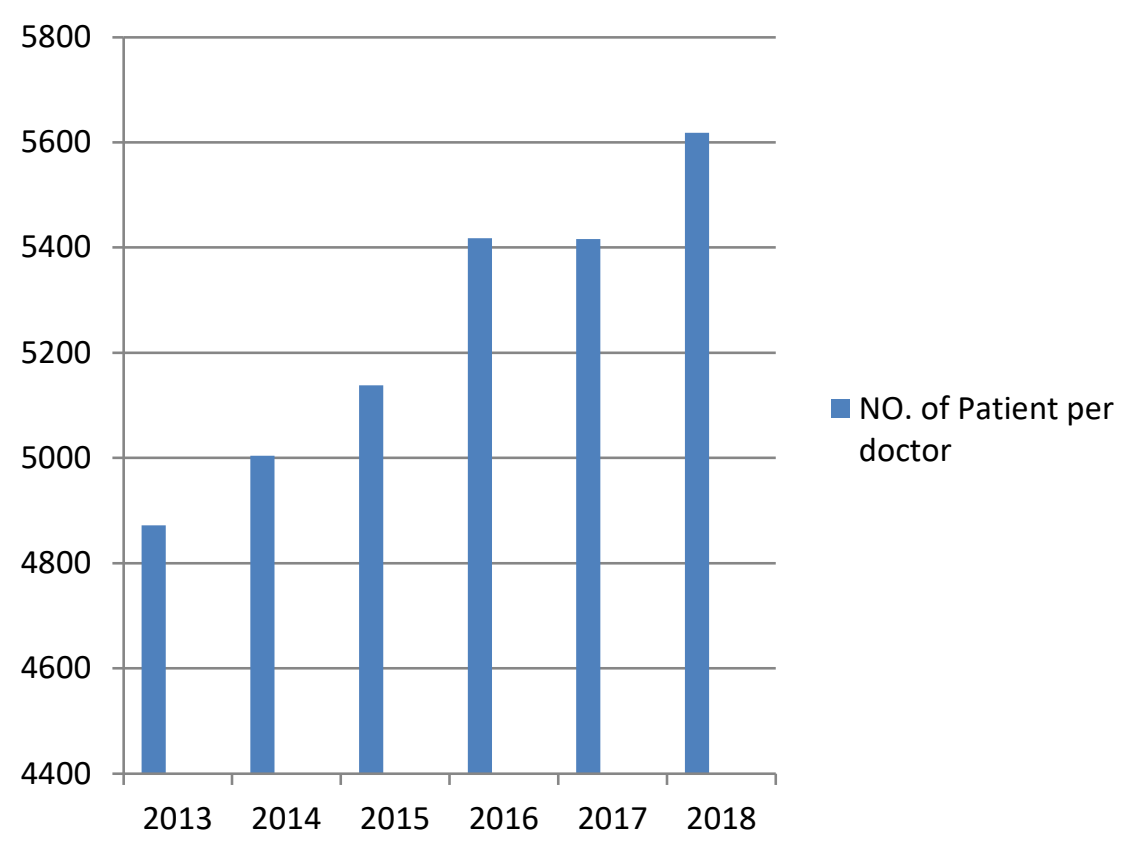

Fig. 1. Graphical representation of the number of patients assigned to a doctor from 2013 till date as drawn from the review 